\title{
Oportunidades de beber a bordo: características do labor naval
}

\section{| ${ }^{1}$ Elizabeth Espindola Halpern, ${ }^{2}$ Ligia Costa Leite I}

Resumo: Uma pesquisa qualitativa foi realizada por meio de um estudo de casos múltiplos e explanatório de modo a investigar o papel da Marinha do Brasil na construção do alcoolismo dos pacientes de um ambulatório especializado em dependência química e examinar como ocorreu o adoecimento desses pacientes no ambiente laboral. Portanto, foram realizadas entrevistas individuais com 13 pacientes de dois grupos terapêuticos do Centro de Dependência Química (CEDEQ). A amostragem, a coleta, análise e interpretação dos dados foram feitas de forma circular. Os resultados apontaram que existem características do trabalho e oportunidades de beber relacionadas à produção do alcoolismo. Em conclusão, modos de consumir bebidas, geralmente em grupo, estão associados à execução das tarefas, facilitando a instalação da dependência do álcool.

> Palavras-chave: alcoolismo; saúde ocupacional; condições de trabalho.
1 Psicóloga e Capitão de Fragata da Marinha do Brasil; doutora em Saúde Mental pelo Instituto de Psiquiatria da Universidade Federal do Rio de Janeiro, Rio de Janeiro, Brasil. Endereço eletrônico: espindolahalpern@ yahoo.com.br

2 Doutora em Comunicação pela Universidade Federal do Rio de Janeiro; professora colaboradora do Instituto de Psiquiatria da Universidade Federal do Rio de Janeiro, Rio de Janeiro, Brasil. Endereço eletrônico: ligia. cleite@gmail.com 
A Marinha do Brasil (MB) criou, em 1997, um ambulatório especializado no tratamento da dependência química, o Centro de Dependência Química (CEDEQ), sediado em um hospital militar, incumbido de tratar militares por meio de terapia de grupo ou individual e acompanhamento medicamentoso. O CEDEQ foi uma iniciativa pioneira da MB no âmbito das Forças Armadas brasileiras, um marco que refletiu o início oficial das ações voltadas à dependência química. Apesar dos avanços das ações na área da prevenção, tratamento e reabilitação, pouco se conhece sobre o impacto que o ambiente laborativo naval exerce na instalação do alcoolismo dos pacientes. Os estudos inaugurais sobre esse tema foram feitos recentemente derivados das investigações realizadas no universo do CEDEQ (HALPERN; FERREIRA; SILVA FILHO, 2008; HALPERN; LEITE; SILVA FILHO, 2010; HALPERN; LEITE, 2010; 2011a; 2011b; 2012a; 2012b; 2013a; 2013b; 2013c). Vale ressaltar que este artigo é fruto de uma das vertentes da pesquisa sobre alcoolismo no ambiente laboral da MB. Para fins desta exposição, serão abordadas algumas das principais constatações desses estudos.

Nas entrevistas com os pacientes, observou-se o entrelace entre sua trajetória de envolvimento com o álcool e suas experiências no trabalho naval. A correlação entre esses dois universos ajuda a esclarecer como se deu a instalação progressiva do alcoolismo nesses pacientes e qual o papel da MB na construção desse fenômeno.

\section{Descrição do campo}

O tratamento em terapia de grupo se desenvolve ao longo de cinco etapas: grupo motivacional, fases I, II, III e grupo de consolidação. Dependendo do aproveitamento individual, a permanência em cada fase variará. Espera-se, sobretudo, que o indivíduo alcance a abstinência e experimente mudanças nas suas formas de agir e pensar. O programa de tratamento prevê que as fases tenham atividades e objetivos específicos a serem alcançados, incluindo a leitura de textos, palestras, apresentação de filmes, embasando-se em técnicas comportamentais e nos 12 Passos e nas 12 Tradições dos Alcoólicos Anônimos (AA). Por influência dessas diretrizes, o tratamento privilegia o atendimento em grupo, acreditando que a ajuda mútua facilita a superação da adicção (ALCOÓliCOS ANÔNIMOS, 1996). 
Apesar de o CEDEQ estar aberto a todo o pessoal militar da MB acima dos

18 anos de idade, a totalidade dos pacientes faz parte da carreira das praças ${ }^{1}$; os oficiais raramente procuram esse ambulatório, optando por consultas particulares. As graduações das praças incluem: marinheiro, soldado, cabo, terceiro-sargento, segundo-sargento, primeiro-sargento e suboficial. Elas são a maioria numérica da organização e estão na base da pirâmide da cadeia de comando. Em geral, são responsáveis pela manutenção e operação dos equipamentos e pela conservação de compartimentos de suas unidades militares (BRASIL, 1980).

A pesquisa foi deferida pelo Comitê de Ética em Pesquisa da MB, cadastro FR $n^{\circ} 306557$ e CAAE no 0021.0.221.000.09, em 14 de dezembro de 2009.

\section{Método, processo de coleta e interpretação de dados}

Realizou-se uma pesquisa qualitativa, através de um estudo de casos múltiplos (comparativo), investigando-se a construção do alcoolismo a bordo e dando relevo à relação dos sujeitos com o contexto nos quais eles estão inseridos, e explanatório, examinando como ocorreu o adoecimento desses pacientes no ambiente laboral, colhendo e analisando informaçōes no decorrer de um determinado período (YIN, 2005). Para tal, foram conduzidas entrevistas individuais e semidirigidas (open-ended) (FOSSEY et al., 2002) com 13 pacientes selecionados dentre os 20 a 25 que faziam parte de dois grupos motivacionais, etapa corresponde à primeira fase do tratamento no CEDEQ. Vale ressaltar que foram usados nomes fictícios para preservar o anonimato de todos os pacientes.

A amostragem, coleta, análise e interpretação dos dados ocorreram de forma interativa (circular), não sequencial (TESCH, 1990; MAXWELL, 1996; FOSSEY et al., 2002; WHITLEY; CRAWFORD, 2005), admitindo a realização de feedback loops (retroalimentação) (WHITLEY; CRAWFORD, 2005). Portanto, em vez de seguirem um percurso linear, as etapas fluíram de modo dinâmico, desembaraçadas de um roteiro estanque a ser cumprido, em torno das trajetórias de envolvimento com o álcool e do labor. Elas colocaram em evidência cinco temas que se mostraram mais centrais: características laborais e as oportunidades de beber, representações de adoecimento, representações de cura, rótulos e modos de beber. Este artigo se aterá às oportunidades de beber a bordo e às características do labor naval. 


\section{Resultados e análise das entrevistas com os pacientes}

\section{Características laborais e as oportunidades de beber}

Para que se possa apresentar e analisar os resultados, considera-se relevante esclarecer alguns conceitos propostos pelas autoras em outras oportunidades.

Primeiramente, o conceito de habitus alcoólico, que congrega a noção de habitus proposta por Bourdieu (2007), aplicando-a a um padrão de comportamento, atitudes e pensamentos relacionados às maneiras de ingerir etílicos. Trata-se de um tipo de tradição, postural e gestual, que vai sendo paulatinamente incorporada. Tal como uma linguagem, impregnada de sentido, o habitus alcoólico é progressivamente sedimentado entre os militares, fruto de aspectos idiossincráticos da vida e cultura navais, associado a práticas do beber coletivo, modos, gírias, piadas e trejeitos. Nessa dinâmica, um contingente de adeptos é "treinado" a beber no decorrer da carreira naval, aumentando o risco de desenvolverem a dependência química. Trata-se de um consumo que não se esgota em função dos efeitos fisiológicos produzidos pelo uso da substância, mas que está entranhado nas vidas desses militares.

A seguir, a noção proposta de trabalhos marinheiros (HALPERN; LEITE; SILVA FILHO, 2010; HALPERN; LEITE, 2013a), que diz respeito às atividades relacionadas às condições, à organização e aos processos laborais navais, sintonizadas com as exigências da lógica da produtividade. Eles são capazes de adoecer os trabalhadores, podendo provocar sofrimento psíquico e expô-los a riscos (DEJOURS, 1987; SELIGMANN-SILVA, 1995).

Por fim, o comportamento etílico naval, experiência que procura ressaltar modos de ingerir bebidas no ambiente naval, inseridos no cotidiano laborativo:

Trata-se de um comportamento imiscuído à jornada de trabalho, que não apenas abarca o momento da ingestão da substância em si, mas que se encontra presente em diversas situações do dia a dia. Ele tem início com o planejamento, em grupo, de oportunidades de beber, até a sua materialização: o ato de beber propriamente dito (HALPERN; LEITE, 2011b, p. 187).

Embora o alcoolismo dos pacientes do CEDEQ possa ser enquadrado a partir dos critérios dispostos nos manuais diagnósticos oficiais, ele geralmente é identificado no espaço laboral quando os padrōes de consumo trazem prejuízos a bordo. Com efeito, os relatos dos pacientes sugerem a influência de determinados aspectos do trabalho naval na instalação progressiva do alcoolismo. 
O $3^{\circ}$ Sargento Américo, 30 anos, solteiro, considerou que a condição de embarcado em um navio estimulou seu consumo de álcool. De um lado, parece haver formas previstas para o consumo oficial, tal como no evento chamado de "salva terra":

Acho que a senhora [entrevistadora] conhece o que se chama de 'salva terra'. É uma comemoração que o navio faz um dia antes de chegar em qualquer porto. Era distribuída, ou a gente mesmo comprava, mas aí já extrapolava! Normalmente, o 'salva terra' seria na noite anterior.

O "salva terra" é uma das tradições navais associadas ao álcool, saudando a aproximação do porto, que serve como atenuante da vida áspera a bordo. Contudo, o próprio militar reconheceu que ocorre uma extrapolação do uso de álcool, que começa antes do horário previsto. No entanto, espera-se que a tripulação saiba gerenciar esse uso de forma a não atrapalhar o serviço, como Américo ressaltou:

Entrevistadora: Mesmo os que estavam trabalhando bebiam?

Américo: Sim. Por mais que eu chegasse 'chapado' em cima de uma carta náutica, eu sou um bom profissional [falou com orgulho]. Álcool nunca me deixou sem condições de trabalhar. De forma nenhuma deixei!

$\mathrm{Na}$ sequência de seu relato, o entrevistado informa que a ingestão de etílicos acabou comprometendo sua vida no navio desde que ele rompeu com os modos tradicionais de consumo:

Sou um cara de sair sozinho, e quase que eu perdi o navio. Aí, o comandante, pra não correr o risco de atrapalhar o resto da tripulação, me tirou do navio. Eu saía com eles, mas depois eu não gostava, eu não conseguia. Já se tornou uma coisa minha, particular, beber, sentar sozinho. O comandante falou: 'Desculpa, você é uma ótima pessoa, mas não vai sair com a gente não'.

Embora Américo pudesse ter sido tecnicamente competente, ao que parece, não foi seu atraso para embarcar que o levou a ser excluído da tripulação do navio, mas o fato de ter bebido sozinho, descumprindo as sociabilidades prescritas. Assim, o comandante solucionou o paradoxo interno entre a proibição e o incentivo ao consumo de bebidas com a expulsão do elemento que destoou do conjunto. A competência profissional de Américo não foi suficiente para mantêlo no navio. Aparentemente, o consumo de bebidas durante a jornada de trabalho não foi percebido pelo comandante como um problema; em contraste, o atraso de Américo para embarcar foi considerado um fator prejudicial à tripulação. 
Ao romper com as tradições navais, o "mau" bebedor precisaria ser proscrito, pois infringiu as regras de etiqueta, prejudicando o funcionamento de uma mecânica cerimonial que estabelece e consolida o lugar do sujeito na hierarquia e seu grau de prestígio (ELIAS, 1987). Embora muitos militares bebam no horário de trabalho, causando transtornos administrativos, nem todos serão rotulados como "problema". Eles serão condenados quando as falhas no trabalho relacionadas ao uso de etílicos se tornarem frequentes e acentuadas, impossibilitando seu mascaramento ou disfarce.

Américo foi um dos pacientes que sinalizou a existência de oportunidades para ingerir etílicos a bordo:

A Marinha incentiva a beber. Ah, acontece muita coisa. Além do navio em si mesmo, do próprio proporcionar bebidas a bordo. A gente sai de porto em porto também. Há o estresse, sabe, interno também.

Com efeito, ele ponderou em que medida a vida na Marinha facilitou o seu hábito de beber álcool:

De certa forma, a vida naval me empurrou para o álcool, porque aí já entra naquela de embarcado, muita ida pro 'soco' [saídas para namorar e beber], muita gente pra beber, isso influenciou um pouco sim.

Wando, 10 Sargento, separado, 42 anos, usuário de álcool, contou que seu consumo abusivo também não passava despercebido pelos amigos da rua, que o apelidaram de "latinha". Embora estivesse constantemente de ressaca, foi enfático ao dizer que não deixava de trabalhar e que não foi punido a bordo. Nesse contexto, aludiu à existência dos bares e dos happy hours na hora do almoço no trabalho:

Wando: Mas sempre tem [bebidas alcoólicas], agora é que tem um bar, montaram um bar pros sargentos, lá. Têm vários happy hours que eu nem aparecia [inaudível].

Entrevistadora: A que horas?

Wando: A partir de 11 e meia, aí vai até uma e meia da tarde, duas horas. Às vezes tinha uma cachacinha pra almoçar, às vezes 'pagavam um limão' [distribuíam caipirinha], no 'rancho' [refeitório].

As falas do $2^{\circ}$ Sargento Pedro, 38 anos, fuzileiro naval, solteiro, sem filhos, ajudam a iluminar a disponibilidade de beber e as sociabilidades associadas a bordo:

A Marinha facilitou pra eu beber. Eu era moleque, entrei com 17. A Marinha em si não me fez beber. Os colegas, né?! Levava já a cachaça já pras manobras, no meio do mato, já comprava já. Era aquela brincadeira! Não tem como tomar cerveja no meio do mato, a gente levava a cachaça. Leva o 'tubo' [cachaça em um galão] e o 'edredon líquido’ [cachaça para aquecer], faz frio à noite. 
Embora reticente quanto ao papel direto da Marinha em tê-lo feito beber, Pedro mostrou como a libação em grupo encontra-se imiscuída nas manobras militares, tendo como argamassa o prazer para consolidar essa experiência.

Rodrigo, cabo carpinteiro, 41 anos, separado e pai de quatro filhos, contou como a oferta de cachaça no navio estava associada ao trabalho:

Na Marinha, se o cara bebe, a tendência dele é beber mais. Qual navio que não libera cachaça direto? TODOS ELES! TODO NAVIO LIBERA! [ênfase]. Eu passava uma semana em casa, um mês fora [alternando entre a casa e as viagens a serviço], a Marinha sugando a gente de todo o jeito.

Essa experiência denota a visceralidade da MB com seus integrantes; em resposta, eles podem se sentir "sugados". A dinâmica laborativa naval muitas vezes exige a presença do militar a bordo sem previsão de voltar para casa, impondo um regime inconstante e imprevisível. Nesse panorama, as bebidas agem como uma válvula de escape, reduzindo os efeitos da disciplina e da autocoação. Driblando a compartimentalização dos espaços e modelagem dos indivíduos engendrada pela organização militar, minorias circunscritas no sopé da pirâmide hierárquica constroem seus universos com regras próprias, oásis que servem de refúgio:

Toda a oficina tem sempre a bendita cachaça. QUALQUER OFICINA, EM QUALQUER QUARTEL, SEMPRE TEM [ênfase]. Tem sempre um grupinho ali. Pode não ter numa oficina, mas na outra tem. TEM SEMPRE ISSO [ênfase].

Rodrigo procurou demonstrar que o consumo de etílicos pode ser generalizado, empregando constantemente as palavras "sempre" e "tem". Ainda que um grande número de militares possa estar envolvido, as experiências com as bebidas foram capitais na experiência pessoal dele. No entanto, os pacientes comentam que existem bebidas nos departamentos, nas oficinas, nos gabinetes e alojamentos, assim como há a tendência a se constituírem grupinhos com normas próprias, senhas de acesso e códigos de conduta, como uma "realidade paralela" que concorre com a organização oficial. Diante da impossibilidade de se confrontar com o sistema primordialmente gerido pela oficialidade, eles criam uma "realidade alternativa" nas franjas do cotidiano naval. Conforme suas possibilidades e necessidades, eles transitam entre as esferas "oficial" e "oficiosa", alternadamente, gerenciando-as ao longo do dia.

No espaço subterrâneo, o álcool parece servir, ao mesmo tempo, de objetivo e pretexto. A meta central dessas agremiações gira em torno do consumo de bebidas e do preparo das oportunidades de beber, dentro e fora do expediente; 
porém, ainda que inconscientemente, as práticas de beber seriam um elo entre os "sócios", que lhes permitiria formar um contrapoder, uma tática para minimizar os efeitos da dominação e da submissão que costumam engendrar a resignação (WEBER, 1999). Nesse refúgio idealizado, o prazer impera, apaziguando desgostos. Enquanto os trabalhos marinheiros são cumpridos, os efeitos balsâmicos do álcool se fazem presentes nas maquinaçôes coletivas para beber, subtraindo o peso das tarefas, reduzindo o período de latência para alcançar esse gozo, porque a libação não precisa aguardar o final da jornada de trabalho. Tão logo encontram uma brecha, garrafas e latinhas os aguardam no perímetro do próprio local de trabalho, aplacando as tensões e o sofrimento.

João, 3o Sargento, 45 anos, casado e pai de uma filha, revelou que a Marinha não correspondeu às suas fantasias de garoto: "a Marinha não foi o que eu esperava. Quando a gente é jovem, faz mil fantasias, sonhos, viagens". Tardiamente, concluiu que tinha pavor de navio: "Eu tenho pavor de navio. Servi um ano embarcado lá em Natal, quando eu era marinheiro ainda. Eu era muito mareado, mareava [enjoava] bastante”. Mesmo assim, ele fez questão de afirmar que a Marinha não foi culpada, dirigindo suas queixas aos integrantes da instituição naval:

Pra falar a verdade, a culpa não foi da Marinha, foi minha! Eu não tenho do que reclamar, a Marinha é boa! Agora, certas pessoas que, no decorrer dessa trajetória, me decepcionaram e me agrediram moralmente, isso aí é que veio desestimulando.

No imaginário do contingente naval, um mecanismo tende a ser acionado coletivamente para proteger a ideia mítica de uma "Marinha-mãe" que é "boa", conservando-a intocada e isenta da responsabilidade pelos desacertos ocorridos no trabalho. Há uma crença na existência de uma porção essencial que subsiste para além daquilo o que ocorre em seu interior, distinta dos relacionamentos produzidos em seu âmago. Imputa-se a culpa no "sistema", tal como João destacou: "O SISTEMA TODO É TERRÍVEL! [ênfase] Então cheguei no ponto, VOCÊ TAVA A PONTO DE EXPLODIR". Portanto, ainda segundo o entrevistado, os desafios ao cumprimento dos trabalhos marinheiros, incluindo as condições e processos de trabalho adversos, encontram nas experiências etílicas uma forma de compensação:

Quando chegava no porto, a galera queria mais é tirar aquela pressão toda! Às vezes, saía de madrugada, todo arrebentado do serviço; daqui a pouco toca 'postos de combate' [exercício de combate] na hora que você ia dormir. Isso aí acontecia sempre. 
As condições laborativas em pauta costumam abranger os desconfortos inerentes à vida de embarcado: temperaturas altas nos locais próximos às máquinas, crueza das instalaçôes, odores de diesel e de outras substâncias tóxicas, camas desconfortáveis em espaços apertados (beliches ou treliches), barulhos e ruídos intensos, exposição a ventos, chuvas, frio e/ou luz solar intensa, náuseas provocadas pelo jogo do navio quando o mar está agitado, dentre vários fatores. Os processos de trabalho se referem às simulações de guerra, exercícios táticos (alguns sem aviso prévio), atividades extenuantes, mantendo toda a tripulação em permanente estado de prontidão, sem conhecerem detalhes da missão (duração, destino ou objetivos).

Ames et al. (2009) revelaram que a natureza do ambiente de trabalho da Marinha norte-americana conduz ao consumo de álcool mais pesado para os militares do que para os civis. Muitos aspectos específicos dessa organização militar contribuem para problemas com bebidas, pois há uma cultura que enfatiza o beber como um mecanismo de alianças, recreação e alívio de estresse. João, por sua vez, deixou patente que haveria uma farta disponibilidade de bebidas no universo naval:

O sistema na Marinha, ou você bebe ou você é de alguma religião. Sempre bebemos, tanto a bordo, nas comemoraçôes, aqueles aperitivos do 'rancho' [refeitório] do navio que eu servi também, quando faz a 'baldeação' [limpeza do navio]. Na 'baldeação' era liberado! E era CACHAÇA MESMO! [ênfase].

O conteúdo das narrativas de João coincidiu com os resultados das pesquisas conduzidas por Ames et al. (2007) com as praças e os oficiais da Marinha norteamericana sobre o uso de etílicos nas organizações militares, constatando a existência de um contexto cultural associado ao comportamento de ingerir álcool, bem como a ambivalência das políticas do álcool, a busca por descontração em razão do estresse laboral e a manutenção das antigas tradições de beber.

O 3o Sargento Wilson, 46 anos, casado e pai de uma filha, ao ser perguntado quando percebeu que estava com algum "problema de saúde”, respondeu: “

Quando? [hesitação] Foi quando isso foi causando uns problemas no trabalho, de faltar a bordo, entendeu?! E outros problemas... [hesitação]. Problemas com o meu encarregado, de relacionamento.

Inicialmente, observa-se a atitude vacilante de Wilson, aspecto comum em alguns pacientes do CEDEQ. Usualmente, eles parecem reticentes, ouvem mais do que falam e têm baixa autoestima. Com uma postura encurvada, olhar 
assustado e cabeça baixa, eles se esquivam nos cantos das salas de atendimento em grupo. Por detrás do jeito hesitante, guardam muita raiva e ressentimento, direcionando-os contra o sistema naval, que, comumente, exige dedicação exclusiva, dificultando a ida ao CEDEQ:

Quando eu pedia um tratamento, o que é que acontecia? Eu viajava! Até hoje eu tô embarcado. E o meu encarregado faz o quê? Ele manda viajar. Tem muita interrupção. No ano passado interrompi, umas duas ou três vezes, viajando!

A mera solicitação para fazer o tratamento pode ser interpretada como uma tentativa de solapar o trabalho. Em resposta, um clima de desconfiança emerge, sobretudo quando os indivíduos têm um histórico de indisciplina, etilismo e de contravençōes disciplinares. Contudo, os questionamentos sobre a veracidade do sujeito precisar se ausentar da unidade militar para resolver problemas particulares não são feitos à toa. Histórias mirabolantes são frequentemente contadas para justificar faltas e atrasos, muitos deles decorrentes de escapadas para farrear, deixando os encarregados inseguros quanto à verdade de suas justificativas. Por isso, exigem sua plena comprovação, preferencialmente, documental (apresentação de atestado médico, por exemplo). Logo, se o indivíduo já é "queimado", ou, melhor, carrega o estigma da má fama, as incertezas sobre suas atitudes são aumentadas. No caso de Wilson, a postura inflexível de seu superior hierárquico ajudou a reforçar essa ciranda mórbida:

Às vezes eu pedia uma licença pra ele [encarregado], e ele: 'Pra que você tá pedindo licença? Pra ir beber?'. Às vezes eu precisava resolver um problema particular. Não conseguia. Quando era no outro dia, eu não vinha pra bordo. Aí, ele me prendia! Fui punido dentro dessa situação, várias vezes.

Ainda que acabem sendo sucessivamente punidos, não sabem como reagir de outra forma, eternizando sua condição de des-a-filiados no interior da instituição. Segundo Castel (1998), na desafiliação social, o sujeito vai perdendo progressivamente posições sociais e no mundo do trabalho, e os laços familiares/ comunitários tornam-se precários até atingir a miséria e o isolamento social.

Para resguardar sua autoridade diante dos subordinados, o encarregado pode negar ou restringir os pedidos particulares para não ser visto como "trouxa". Existe muita pressão na linha de comando sobre as chefias para que saibam liderar e controlar seu pessoal. Daí a propensão a serem reticentes com os "militaresproblema”. A falta de preparo para lidar com o seu pessoal, somada à carência 
de informações sobre a dependência química, acaba deixando-os inseguros. Em resposta, eles podem deliberar de forma autoritária, compensando a sensação de impotência. Vale esclarecer que é muito comum que os superiores hierárquicos sejam muito mais jovens do que seus subordinados, especialmente quando os oficiais são tenentes ou capitães-tenentes, com pouco mais de 30 anos. Em contraste, os subordinados, além de serem geralmente mais velhos, têm mais tempo serviço e de experiência na Marinha. Por conseguinte, fazer-se respeitar por suas qualidades pessoais e profissionais é uma questão desafiadora.

As vivências de Manoel, suboficial, 47 anos, com a especialidade de escrevente, enfatizam questão do estresse para "esquecer" os problemas:

Manoel: Infelizmente, na Marinha, TUDO É PRA ONTEM [ênfase], tem um monte de computador, mas a autoridade QUER O PAPEL [ênfase].

Entrevistadora: Por que a Marinha quer pra ontem?

Manoel: Porque tem muita gente que quer 'mostrar serviço' [ostentar trabalho], e eles 'mostram serviço' assim.

Manoel acabou repetindo várias vezes o mesmo exemplo sobre a pressão administrativa que sofreu diariamente, ainda mais pelo fato de sua especialidade na Marinha ser a de escrevente, ou seja, incumbido de lidar com documentos considerados urgentes. De fato, é uma característica do cotidiano naval que qualquer tarefa tenha um prazo mínimo para a sua prontificação, ou seja, os encarregados, ao "distribuírem as faxinas" (delegarem as tarefas), estabelecem que seus subordinados as executem "para ontem”, imprimindo um clima de emergência perene. Ainda que seja notório o fato de não haver motivos para tal urgência, todos são envolvidos pela pressão e, sobretudo, pela ameaça, ainda que velada, de punição.

O 2o Sargento José, pai de três filhos, casado, 45 anos, natural do Rio de Janeiro, começou a usar álcool, cocaína e maconha aos 40 anos, impulsionado pela curiosidade por tantos anos reprimida. Seus relatos ajudam a esclarecer mais sobre as oportunidades de beber a bordo:

José: Geralmente, quando o navio chega no porto, TEM AQUELE 'RASGA' [enfático].

Entrevistadora: Tem o quê?

José: 'Rasga', quando o navio vai atracar, na véspera da atracação. É liberado [sic] cerveja, whisky. 
Esse tipo de cenário é bastante comum no cotidiano naval, não só para aqueles que servem nos navios, mas também para os que trabalham em terra. O "rasga" pode ter outras denominações; cada área da Marinha cria seus próprios apelidos. As formas e os motivos para beber são variados: durante a jornada laboral, podem ocorrer nos eventos, antes, durante e após o expediente, nas cerimônias; enfim, cada paciente revelou um tipo diferente de prática, fruto da subcultura local. Cabe ressaltar que existem universos culturais distintos dentro da própria Marinha, cada qual com suas idiossincrasias; contudo, apesar das diferenças, prevalece o gosto pelo álcool. Nesse episódio, José descreveu um motivo que pode levar uma praça a ser colocada no Livro de Registro de Contravençôes:

Lembro que teve um dia que ficamos até três horas da manhã servindo whisky, cerveja [em cumprimento à sua especialidade de taifeiro, de servir comidas e bebidas]. Fui acordar às oito horas da manhã e aí o Chefe do Departamento disse que eu tava no Livro [de Contravençôes]. Disse que eu 'queimei' [perdi] a 'parada' [reunião geral]. Fui pra audiência [reunião com o comandante do navio] e disse: 'Puxa, comandante, fiquei servindo até três horas da manhã, só fui dormir depois'. Mas ele disse: 'Isso não justifica'.

Ser colocado no Livro de Contravenções Disciplinares refere-se a uma sistemática por meio da qual um oficial registra a ocorrência de uma contravenção. Cabe à maior autoridade da unidade do militar julgar o fato, verificando em qual item do Regulamento Disciplinar para a Marinha $\left(\mathrm{RDM}^{2}\right)$ (BRASIL, 1983) ele se aplica. Como parte do protocolo do julgamento, o militar deve comparecer à audiência com o comandante, quando será ouvido; em seguida, os fatos são apurados para decidir qual punição será aplicada.

Embora o artigo $27^{\circ}$ do RDM estabeleça que a autoridade deva julgar a gravidade da contravenção com imparcialidade e isenção de ânimo, sem condescendência nem excessivo rigor, considerando as circunstâncias justificativas ou atenuantes, nem sempre isso acontece. $\mathrm{O}$ comandante raramente discorda do lançamento feito pelo oficial que registrou a ocorrência no livro, sobretudo para não desprestigiar sua decisão. Ainda que o artigo $26^{\circ}$ determine que nenhuma pena seja imposta antes do contraventor ser ouvido e dos fatos serem apurados, na prática, as justificativas da praça não costumam ter o poder de influenciar a decisão final do comandante.

A transcrição das penas é feita na Caderneta Registro, de onde consta o histórico profissional do contraventor. Além do episódio ficar registrado de forma indelével em algumas folhas de papel, ele fica marcado na subjetividade 
do militar. As lembranças das humilhações subjacentes não são apagadas da memória. Inclusive, a forma como elas são declaradas contribui para que sejam lembradas, não apenas pelo contraventor, mas também pelo grupo, de forma exemplar. Quanto mais "moderno" (menos graduado) for o contraventor, mais ampla será a divulgação oficial de seu erro. No cotidiano laborativo da Marinha, as praças são permanentemente perseguidas pelo espectro do RDM, sempre à espreita para enquadrá-los. Dentro desse espírito, José confirmou que o impulso de usar bebidas seria movido principalmente pelos sentimentos de injustiça:

Esses sentimentos de injustiça foi [sic] uma das causas pra eu querer usar, principalmente pro pessoal que serve embarcado.

A disponibilidade do álcool foi reconhecida como um fator de risco para o aumento do consumo nos locais de trabalho (AMES; GRUBE, 1999). Estudos conduzidos por Ames et al. (2004) demonstram a existência da oferta de bebidas e de oportunidades para beber nas bases militares, nos quartéis, nos bares e nos hotéis próximos às unidades militares, influenciando o beber pesado e o uso abusivo entre jovens militares norte-americanos. Por fim, os militares se deparam com o desafio constante de ter que lidar com a disponibilidade física e social das bebidas alcoólicas, ainda mais no caso de José, taifeiro.

\section{Discussão}

De modo recorrente, os pacientes atribuíram às condições, aos processos e à organização do trabalho, peculiares à vida naval, a facilitação de sua busca por substâncias psicoativas, sobretudo o álcool, denunciando a ampla distribuição de bebidas e de oportunidades para consumi-las.

Todavia, as entrevistas com os pacientes sugeriram que a experiência do sofrimento nem sempre foi claramente reconhecida pelo próprio sujeito. Dejours (1987) acredita que esse aspecto possa estar relacionado, em um primeiro momento, ao fato de ele estar tão envolvido com as tarefas que acaba tendo sua vida mental dominada pela organização do trabalho; porém, a seguir, seus desejos acabam sendo silenciados, de forma imposta. Muitos revelaram que, diante de certas situações de poder e de dominação, refugiaram-se no álcool, ocultando sentimentos de vergonha e de impotência. Em resposta à coerção: o silêncio. "A vergonha é um sentimento doloroso e sensível sobre o qual é preferível não falar. Ela engendra o silêncio, o fechamento em si até 
a inibição" (GAULEJAC, 2006, p. 17). Entregando-se à bebida, o militar tenderia a internalizar ainda mais uma imagem negativa de si, alimentando esse círculo vicioso, destruindo as possibilidades de se revoltar, reagir e agir, impulsionando-o, progressivamente, em direção ao "copo".

O modus operandi das chamadas instituiçôes totais, como descrito por Goffman (1992), consolida sentimentos de apatia e resignação, pois seus integrantes sofrem uma progressiva mutilação do eu. Com efeito, muitos desses pacientes não têm uma atitude de queixa, mas de gratidão à "Marinha-mãe" que os acolheu, alimentou e abrigou. Geralmente, sentem-se culpados ou constrangidos ao criticarem a Marinha, como se fosse uma traição, optando por assumir a maior parcela de culpa pela sua condição. $\mathrm{Na}$ verdade, a percepção de que as condições laborais expõem o trabalhador naval a riscos, colaborando para o uso abusivo do álcool e para a instalação do alcoolismo, é nublada. Entretanto, nas entrelinhas do aparente contrassenso da coexistência de uma "Marinha boa" contra um "sistema mau”, parece residir uma forma disfarçada de violência sobre esses indivíduos. Trata-se da violência simbólica, que, nos termos de Bourdieu (2002), manifesta-se de forma branda e invisível, e, por isso, acaba sendo suportada.

Nos interstícios da execução dos trabalhos marinheiros, impera a vontade de que todos os integrantes da corporação mantenham-se em um estado de vigilância ininterrupto, uns sobre os outros, submetidos à eterna pirâmide de olhares. A todos compete o papel de impositores de regras, cabendo aos mais graduados uma fatia maior dessa responsabilidade, tarefa que se cumpre por haver um “(...) olho perfeito a que nada escapa e centro em direção ao qual todos os olhares convergem" (FOUCAULT, 2007, p. 146). Essa modalidade de capilarização do poder está materializada em documentos normativos, tais como a Ordenança Geral para o Serviço da Armada (OGSA) (BRASIL, 1987). Ela estipula como se deve alcançar a correta condução das atividades diárias nas unidades militares, visando ao bom desempenho profissional, de modo uniforme e eficiente.

Adicionalmente, a OGSA exorta os militares a zelarem pelo funcionamento da organização naval, a nível material e pessoal, mantendo um padrão exemplar de funcionamento, em constante supervisão. Desse modo, considera-se que todos são individualmente responsáveis, dentro de sua esfera de ação, seja por negligência, imprevidência, fraqueza ou falta de energia no cumprimento de deveres e no desempenho de suas atribuições. O emprego do jogo do olhar 
(FOUCAULT, 2007) dá vida à OGSA, aciona a vigilância hierárquica, desmascarando, por meio da aplicação de técnicas coercitivas, aqueles que não respondem às exigências laborais, recrudescendo as fronteiras entre o "certo" e o "errado". Incapazes de serem peças da engrenagem naval para manterem em funcionamento equipamentos e navios, aqueles que revelam sua "humanidade", com desejos e limitações, são excluídos, transformando-se em refugos humanos (BAUMAN, 2005). Em resposta, duas estratégias alternativas e complementares são usualmente aplicadas para lidar com os "indivíduos falhos": antropofágicas, engolindo-os para abafar as distinçōes e as diferenças; ou antropoêmicas, vomitando, banindo e excluindo os estranhos (BAUMAN, 1998).

\section{Considerações finais}

Os relatos dos pacientes ajudaram a perceber o sentido da fala de um grupo, que conta o sofrimento de uma classe subalterna desprivilegiada. Em resposta, produzem comportamentos "marginais" (comportamentos etílicos navais) que recusam o costumeiro enquadramento. Escapando das normas organizacionais, eles anseiam pelo extravasamento daquilo que não foi contido, incorporado, manipulado, amoldado ou reprimido. Beber converte-se em um sintoma do "corpo" individual e institucional que fala, e que, enquanto linguagem, é eloquente ao se pronunciar, corajoso ao verbalizar um enviesado "não", contrapondo-se, ainda que inconscientemente, à função restritiva de serem "membros" do "organismo" militar (BRASIL, 1980).

Por outro lado, os pacientes aproveitam-se dessa conexão visceral com a corporação naval para denunciar a existência de um mal estar no cotidiano laborativo, manifestado pelo "corpo" que bebe. Ao serem liberados pelos etílicos, desinibidos, alardeiam o que todo mundo sabe, mas que seria mais difícil de ser verbalizado "de cara limpa" (sóbrios). Os pacientes do CEDEQ são arautos dos sofrimentos vividos na própria pele e também no dorso dos antecessores, "escória imprestável”, "fezes da população" recrutada à força (ARIAS NETO, 2001), condenada às espadadas ou às presigangas (GREENHALGH, 1998). Resquícios de uma época remota ainda presente, não mais evidenciados com o uso escancarado da chibata, mas pela aplicação do crivo inclemente das regras, ao mesmo tempo vacilante e impreciso, que tenta demarcar as fronteiras (simbólicas) entre os "marginais" e os "não marginais". 
A compreensão sobre o funcionamento da "mecânica" do habitus alcoólico que, até então, se fazia invisível, inaudível e imperceptível, é fundamental para conter uma perene fabricação de geraçōes de bebedores navais. Mudar essa cultura pressupõe, em primeiro lugar, o despertar de um "delírio" coletivo que vem mantendo parte do contingente naval refém das ilusōes etílicas de gozo fácil, compulsivas em arrebanhar neófitos. É capital a dissolução das quimeras prometidas de alegrias advindas dos efeitos alcoólicos prazerosos e fugazes que, muitas vezes, usurpam suas vidas, visando libertá-los da vida embriagada. A cada gole incauto entornado, uma gota de vida se esvai, drenando seus recursos pessoais, profissionais e financeiros, em uma transfusão progressiva e implacável, restandolhes, com essa simbiose, uma existência anestesiada, um "eu ébrio" e escravizado, porém, ao mesmo tempo, ajudando-os a lidar com o cotidiano laborativo.

Paradoxalmente, esses modos de beber alforriam gritos sufocados, vozes dos mares, brados saudosos das eras em que os marujos eram desbravadores dos oceanos virgens, explorando terras desconhecidas, inaugurando diferentes perspectivas e alcançando longínquos horizontes. Um tempo que ficou no passado, revivido nas telas hollywoodianas que reencenam uma existência mais audaz, mais pirata, mais heroica, alimentando o imaginário dos recrutas que ingressam nos quartéis, sonhando com aventuras e conquistas. Todavia, para muitos, esse ideal se frustra diante do cotidiano laborativo nada romântico, apartado do sonho pueril. Homem apequenado, formatado, inconformado, que se liberta com o álcool na esperança de ser mais do que lhe é autorizado manifestar. De bar em bar, segue em busca de uma improvável vitória na luta diária pela sobrevivência. Um novo trago amargo na solidão da esquina manifesta um débil pedido de socorro à providência divina para que ele seja arrancado do lodo do poço sem fundo, sem forças para se metamorfosear em seu próprio salvador, incapaz de lutar por sua redenção. Ironicamente, submerso no álcool, ele se agiganta, se pensa grande e volta a ser, momentaneamente, o rei dos mares. ${ }^{3}$

\section{Referências}

AlCOÓlicos ANÔNimOS. O Grupo de AA: onde tudo começa. São Paulo: JUNAAB, 1996.

AMES, G.M.; GRUBE, J.W. Alcohol availability and workplace drinking: mixed method analyses. Journal of Studies on Alcohol, v. 60, n.3, p. 383-393, 1999. 
AMES, G.M. et al. A longitudinal study of drinking behavior among young adults in the military. Paper presented at the Research Society on Alcoholism Annual Scientific Meeting, Vancouver, 2004.

AMES, G.M. et al. Military culture and drinking behavior among U.S. Navy careerists. Journal of Studies on Alcohol and Drugs, v. 68, n. 3, p. 336-344, 2007.

AMES, G.M. et al. The impact of occupational culture on drinking behavior of young adults in the U.S. Navy. Journal of Mixed Methods Research, v. 3, n. 2, p. 120-150, 2009.

ARIAS NETO, J.M. Em busca da cidadania: Praças da Armada Nacional 1867-1910. Tese (Doutorado em História) - Programa de Pós-Graduação em História Social, Universidade de São Paulo, São Paulo, 2001.

BAUMAN, Z. O mal-estar na pós-modernidade. Rio de Janeiro: Zahar, 1998. . idas desperdiçadas. Rio de Janeiro: Zahar, 2005.

BOURDIEU, P. A produção da crença: contribuição para uma economia dos bens simbólicos. São Paulo: Zouk, 2002. . O poder simbólico. Rio de Janeiro: Bertrand Brasil, 2007.

BRASIL. Lei n ${ }^{\circ}$ 6.880, de 9 de dezembro de 1980. Dispõe sobre o Estatuto dos Militares. Rio de Janeiro, Serviço de Documentação da Marinha. Diário Oficial da Uniāo, Título I de 11 de dezembro de 1980 .

. Decreto $\mathrm{n}^{\circ}$ 88.545, de 26 de julho de 1983. Aprova o Regulamento Disciplinar para a Marinha e dá outras providências. Rio de Janeiro: Serviço de Documentação da Marinha, 1983.

. Decreto n 95.480 de 13 de dezembro de 1987. Aprova a Ordenança Geral para o Serviço da Armada. Rio de Janeiro: Serviço de Documentação da Marinha, 1987.

CASTEL, R. As metamorfoses da questão social: uma crônica do salário. Petrópolis: Vozes, 1998.

DEJOURS, C. A loucura do trabalho: estudo de psicopatologia do trabalho. São Paulo: Oboré, 1987.

ELIAS, N. A sociedade de corte. Lisboa: Editorial Stampa, 1987.

FOSSEY, E. et al. Understanding and evaluating qualitative research. Australian and New Zealand Journal of Psychiatry, v. 36, p. 717-732, 2002.

FOUCAULT, M. Vigiar e punir: nascimento da prisão. 34. ed. Petrópolis: Vozes, 2007.

GAULEJAC, V. de. As origens da vergonha. São Paulo: Via Lettera, 2006.

GOFFMAN, E. Manicômios, prisões e conventos. São Paulo: Perspectiva, 1992.

GREENHALGH, J.F.L. Presigangas e calabouços ou prisóes da Marinha no século XIX. Rio de Janeiro: Serviço de Documentação da Marinha, 1998. 
HALPERN, E.E.; FERREIRA, S.M.B.; SILVA FILHO, J.F. da. Os efeitos das situaçôes de trabalho na construção do alcoolismo de pacientes militares da Marinha do Brasil. Cadernos de Psicologia Social do Trabalho, v. 11, n. 2, p. 273-286, 2008.

HALPERN, E.E.; LEITE, L.M.C.; SILVA FILHO, J.F. da. Bebendo a bordo: tradição aprendida. Antropolitica: Revista Contemporânea de Antropologia e Ciência Política, v. 28, n. 1, p. 151-176, 1 sem. 2010.

HALPERN, E.E.; LEITE, L.M.C. Lei seca no mar: desafios preventivos na Marinha do Brasil. Arquivos Brasileiros de Psicologia, v. 62, n. 2, p. 103-114, 2010.

- The construction of the alcoholic habitus and alcohol consumption in the workplace among military patients of Brazilian Navy. Cadernos de Saúde Coletiva, v. 19, n. 3, p. 356-365, 2011a.

. Decifrando os significados dos comportamentos etílicos navais de pacientes militares. Boletim de Psicologia, v. 61, n.135, p. 177-191, 2011 b.

- Representações de adoecimento e cura de pacientes do Centro de Dependência Química do Hospital Central da Marinha. Revista Ciência \& Saúde Coletiva, v. 17, n. 4, p. 1079-1089, 2012a.

A farda "siri cozido" e a "branquinha": narrativas de vida de um paciente militar alcoolista. Cadernos de Psicologia Social do Trabalho, v. 15, n. 1, p. 65-80, 2012b.

A interseção entre os trabalhos marinheiros e o alcoolismo. Revista Psicologia: Organizaçôes e Trabalho, v. 13, n. 2, p. 111-126, maio-ago. 2013a.

. Etilismo na jornada laboral: peculiaridades da vida naval. Revista Saúde e Sociedade, 2013b. No prelo.

- Tradições e punições: a cachaça do marujo e o whisky do comandante. Dilemas: Revista de Estudos de Conflito e Controle social, 2013c. No prelo.

MAXWELL, J. Qualitative research design: an interactive approach. London: Sage, 1996.

SELIGMANN-SILVA, E. Psicopatologia e psicodinâmica no trabalho. In: MENDES, R. (Org.). Patologia do trabalho. Rio de Janeiro: Atheneu, 1995, p. 287-310.

TESCH, R. Qualitative research: analysis types and softward tools. New York: Falmer, 1990.

WEBER, M. Economia e sociedade: fundamentos da sociologia compreensiva. Brasília: UnB. 2v., 1999.

WHITLEY, R.; CRAWFORD, M. Qualitative Research in Psychiatry. Canadian Journal of Psychiatry, v. 50, n. 2, p. 108-114, 2005.

YIN, R. K. Estudo de caso: planejamento e métodos. Porto Alegre: Bookman, 2005. 
1 "Praças" é um termo empregado no feminino.

${ }^{2}$ Esse regulamento tem por propósito a especificação e a classificação das contravençôes disciplinares e o estabelecimento das normas relativas à amplitude e à aplicação das penas disciplinares, à classificação do comportamento militar e à interposição de recursos contra essas penas.

${ }^{3}$ E.E. Halpern participou da concepção do texto, análise e interpretação dos dados, redação e revisão do artigo. L.C. Leite orientou a pesquisa de doutorado que originou o artigo e participou de todas as etapas de redação e revisão crítica do artigo. 
Opportunities to drink on board: characteristics of naval labor

A qualitative research was conducted through a multiple case study and an explanatory research in order to investigate the role of Brazilian Navy in the construction of the patients' alcoholism treated in an outpatient chemical dependency and examine how their illnesses occurred in the workplace. Therefore, individual interviews were conducted with 13 patients who belonged to two treatment groups of the Center for Chemical Dependency (CEDEQ). Sampling, data collection, analysis and interpretation of data were conducted in a circular manner. The results showed that there are features of the labor and drinking opportunities related to the production of alcoholism. In conclusion, ways of consuming beverages, usually in groups, are associated with the execution of tasks, facilitating the installation of alcohol addiction.

> Key words: alcoholism; occupational health; working conditions. 